Transportation Research Forum

The Measurement of Grain Barge Demand on Inland Waterways: A Study of the Mississippi River Author(s): Tun-Hsiang (Edward) Yu and Stephen W. Fuller

Source: Journal of the Transportation Research Forum, Vol. 44, No. 1 (Spring 2005), pp. 27-39

Published by: Transportation Research Forum

Stable URL: http://www.trforum.org/journal

The Transportation Research Forum, founded in 1958, is an independent, nonprofit organization of transportation professionals who conduct, use, and benefit from research. Its purpose is to provide an impartial meeting ground for carriers, shippers, government officials, consultants, university researchers, suppliers, and others seeking exchange of information and ideas related to both passenger and freight transportation. More information on the Transportation Research Forum can be found on the Web at www.trforum.org. 


\section{THE MEASUREMENT OF GRAIN BARGE DEMAND ON INLAND WATERWAYS: A STUDY OF THE MISSISSIPPI RIVER}

This paper attempts to estimate structural demand for grain barge transportation on the upper Mississippi River. Results suggest an inelastic demand for grain barge transportation on the upper Mississippi in the short run while the price elasticity increases to 1.0 in the longer run. Additionally, foreign grain demand and domestic grain consumption are found to influence grain barge demand. Also, the winter season and floods affect demand negatively. Hausman's specification test shows the ordinary least square and two-stage least square estimates are statistically invariant.

\section{by Tun-Hsiang (Edward) Yu and Stephen W. Fuller}

The United States is a primary producer and exporter of corn, soybeans, and wheat. Most of the export-bound grain is shipped to Mexico, Asia and Europe through the lower Mississippi River ports, which handles about $75 \%$ of the U.S. annual corn and soybeans outflow. The upper Mississippi River is the primary transportation artery for moving corn, soybeans and wheat production from the north central United States to the lower Mississippi River port area. Historical data show about 45 million metric tons of food and farm products are annually transported to Gulf ports via the upper Mississippi River with 90\% comprised of corn and soybeans (U.S. Army Corps of Engineers, 2002b).

Although the importance of the upper Mississippi to U.S. agriculture is considerable, the studies regarding demand of grain barge transportation on the river, however, are very few. Exceptions include the papers by Harnish and Dunn (1996) and Mijkovic et al. (2000). Harnish and Dunn (1996) estimated a reducedfrom model to explore the determinants of grain barge rates on the Mississippi River system (including Mississippi, Illinois and Ohio rivers) in the short run. They selected eight segments of the river system and conducted an individual and pooled estimation. Their results suggested that grain exports, coal barge rates, input prices (fuel, labor), and distance influence grain barge rates. Miljkovic et al. (2000) conducted a system estimation including both rail and barge transportation modes for export-bound grain movement. Supply and demand equations associated with the rail and barge market linking Illinois to the Gulf of Mexico were evaluated in an econometric approach. The findings suggested these two transportation modes were partial substitutes. The negative own price-quantity relationship was also found in the study. The export grain level, however, did not have a statistically significant effect on the demand for both barge and rail modes. The dependent variable in the demand function was price (barge rate, rail rate), hence the elasticity could not be obtained. Their results suggested that the own price-quantity flexibility of barge demand ranging between -0.485 and -0.541 .

There are additional studies related to grain movement on inland waterways. Hauser, Beaulieu, and Baumel (1985) studied the impact of inland waterway user fees on the grain flow pattern among rail, barge and truck markets, and calculated an implied demand elasticity for barge. Babcock and German (1983) evaluated and forecasted the impact of the diesel fuel tax on the demand for U.S. waterway traffic. Fellin and Fuller (1997) estimated the effect of the waterway user tax on U.S. agricultural and transportation markets. Oum (1979) formulated an intermodal network between rail, road and inland waterways in Canada. Beuthe et al. (2001) employed a detailed multimodal geographic information system (GIS) network model to assess direct and cross-elasticities for rail, road and waterway transport in Belgium. In addition, 
several studies focused on the forecast of barge traffic (Wilson and Sander, 1982; Tang, 2001; Babcock and Lu, 2002).

None of the previous studies yielded direct estimates of the price elasticity for grain barge demand on the upper Mississippi River. The knowledge of grain barge demand on the river is important to the barge industry, farmers, and authorities that maintain and manage the lock system on the river. Understanding grain barge demand would enable the barge industry to provide more adequate service during peak/off-peak periods so their operation costs could be reduced. Grain exporters can also benefit from the knowledge via a better planning of distribution strategy. Moreover, this information is a key input in the economic feasibility analysis of waterway infrastructure improvement. It is particularly critical today because of the controversies regarding the expansion of the aged lock system on the upper Mississippi River. Economic benefits from improving inland waterway transportation infrastructure are conceptually based on a demand schedule that relates barge companies willingness to pay for improved navigability of the waterway. A portion of the area under the demand relationship (consumer surplus) would offer a measure of the gross benefits from the infrastructure improvement. For this reason, knowledge of the demand characteristics for barge transportation on the upper Mississippi is worth exploring. The purpose of this paper is to estimate the structural demand for grain barge transportation on the upper Mississippi River and provide useful information to interest groups.

\section{THEORETICAL FOUNDATION}

Because the demand for grain barge transportation is a derived demand, any factors that shift supply and demand curves in production regions and demand curves in export markets will consequently move the demand for barge transportation (Boyer, 1997). Tang (2001) has an extensive discussion of the demand for grain barge transportation. A two-region spatial equilibrium model is used to illustrate the theoretical foundation of grain barge demand (Figure 1). Panel A depicts the supply $\left(\mathrm{S}_{\mathrm{x}}\right)$ and demand $\left(D_{x}\right)$ of grain (e.g., corn) in the north central United States while Panel $C$ represents the rest-of-the-world's (ROW) excess demand for grain localized at lower Mississippi River ports. Panel B, the trade panel, includes the excess grain supply of the north central region $\left(E S_{x}=S_{x}-D_{x}\right)$ and the excess demand of the foreign regions that purchase grain at lower

\section{Figure 1: Two-Region Spatial Equilibrium Model and Derived Transportation Market}

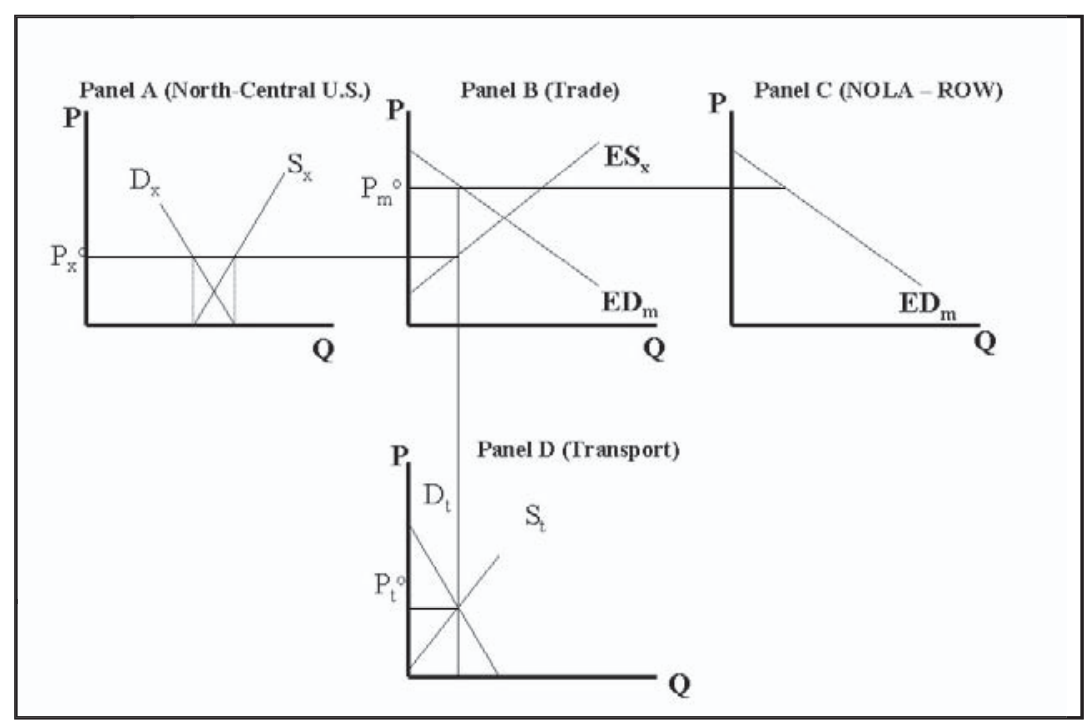


Mississippi River ports $\left(\mathrm{ED}_{\mathrm{m}}=\mathrm{D}_{\mathrm{m}}-\mathrm{S}_{\mathrm{m}}\right)$. The intersection of excess supply $\left(\mathrm{ES}_{\mathrm{x}}\right)$ and excess demand $\left(E_{m}\right)$ relates the equilibrium price and quantity of grain traded between the north central United States and lower Mississippi River ports if no transportation costs were required to link the two regions. However, transportation costs are important in the marketing of grain. The derived demand for grain transportation and the supply of grain transportation service are represented in Panel D. The derived transportation demand is equal to the vertical distance between the excess supply $\left(\mathrm{ES}_{\mathrm{x}}\right)$ and excess demand $\left(\mathrm{ED}_{\mathrm{m}}\right)$ in Panel B. Also shown in Panel D is the supply of transportation service linking the north central United States to lower Mississippi River ports. Because barges transport the majority of grain from the north central region to lower Mississippi River ports (more than 90\%), it is reasonable to assume the supply is representative of the grain barge fleet operating on the upper Mississippi River. The intersection of the derived transport demand and supply determines the transportation rate linking the north central United States to lower Mississippi River ports and the corresponding grain prices in the north central region $\left(\mathrm{P}_{\mathrm{x}}\right)$ and port area $\left(\mathrm{P}_{\mathrm{m}}\right)($ Panel $\mathrm{B})$, where grain prices in the two regions $\left(\mathrm{P}_{\mathrm{x}}\right.$ and $\left.\mathrm{P}_{\mathrm{m}}\right)$ differ by the barge transport rate that link the two regions. Any force shifting the regional supply $\left(\mathrm{S}_{\mathrm{x}}\right)$ and demand $\left(\mathrm{D}_{\mathrm{x}}\right)$ of grain in the north central United States will shift the excess supply of grain $\left(\mathrm{ES}_{\mathrm{x}}\right)$ and the derived transportation demand. Similarly, shifts in rest-of-the-world (ROW) excess demand and supply will also alter the derived demand for transportation. Therefore, these forces need to be considered when estimating the demand for grain barge transportation.

In addition to those forces discussed in the partial equilibrium representation in Figure 1, other important factors such as railroads and the competing transportation service may influence the demand for grain barge transportation. Grain producers in Iowa or Minnesota may find Pacific Northwest ports (PNW) an alternative to lower Mississippi River ports. Therefore, grain demand at Pacific Northwest (PNW) ports and transportation rates linking the upper Mississippi hinterland and the PNW may impact grain barge demand on the upper Mississippi River. In addition, the spread between ocean freight rates from the Pacific Northwest and lower Mississippi River ports to Asia may impact grain barge demand on these waterways.

\section{MODEL SPECIFICATIONS}

Based on the theory discussion above, we suggest important forces affecting grain barge demand on the upper Mississippi River. The grain barge demand function is specified as:

(1) $q_{b, t}=f\left(q_{b, t-i}, p_{b, t}, \operatorname{exd}_{g, t}\right.$, domd $_{g, t}$, doms $\left._{g, t}, p_{o, t}, D_{t}\right)$

where $q_{b, t}$ is the quantity of the grain transportation service purchased by river grain shippers per unit of time t, $p_{b, t}$ is the grain barge rate, exd $d_{g, t}$ is the grain export level, and domd $d_{g, t}$ and doms ${ }_{g, t}$ are the domestic demand and supply of grain, respectively. The variable $p_{o, t}$ is the rate proxy of other transportation modes and $D_{t}$ are weatherrelated and seasonal dummy variables.

Grain barge movement on the upper Mississippi River exhibits significant seasonality (Figure 2); therefore, the quantity of grain moved by barge in previous time periods (either one month or one year past) may provide useful information for the current barge demand. In general, this dynamic relationship can be formulated as an autoregressive distributed lag (ADL) model. Typically, an $\operatorname{ADL}(m, n)$ model represents an equation with $m$ lags of the dependent variable and $n$ lags of the independent variable as regressors. In this study, we attempt to explore the influence of previous barge demand on the current demand, hence, the lag of the dependent variable, $q_{b, t}$, is included in the demand equation. The demand equation then becomes a partial adjustment model: a special case of ADL model (Davidson and MacKinnon, 1993). Furthermore, the lagged structure facilitates the estimation of long-run relationships.

Most obviously, barge rates should be included as an explanatory variable. According to the law of demand, an inverse relationship should exist between barge demand and rate; that is, an increase in the grain barge rate will reduce grain barge demand, ceteris paribus. Clearly, foreign grain demand would appear to have an important impact on the demand for grain barge 
Figure 2: Quantity of Corn and Soybeans Moved by Barge on the Upper Mississippi River, thousand tons

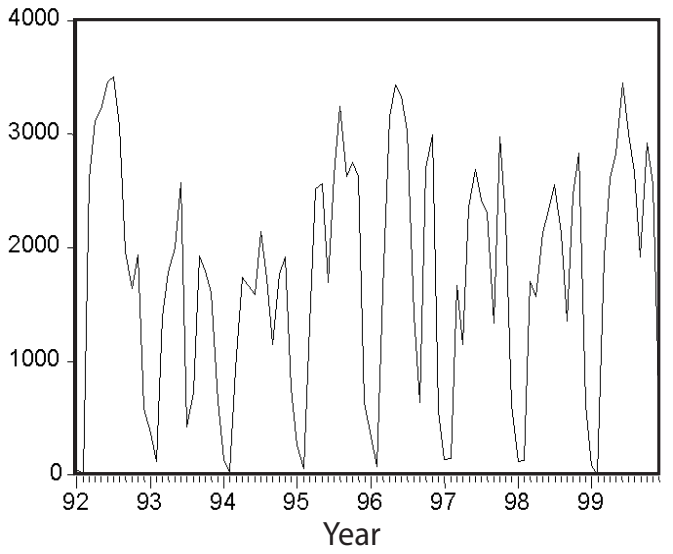

transportation because more than $95 \%$ of grain barge movements on the upper Mississippi River are to lower Mississippi River ports. An increase in foreign grain demand will shift the grain barge demand curve to the right, hence a positive relationship between foreign grain demand and the derived transportation demand. The domestic supply and demand of grain in the north central region is influential in determining grain barge usage. Regional grain supply is expected to affect the derived barge transport demand in a positive manner because an increase in local grain supply will shift the excess supply curve and the grain barge demand curve rightward. In contrast, an increase in regional grain demands will have a negative impact on grain barge transport demand due to the leftward shift of the excess grain supply curve and derived transport demand.

Other transportation modes may also impact grain barge traffic on the upper Mississippi River. For instance, railroads (Burlington Northern-Santa Fe and Union Pacific) operating in Minnesota and Iowa may compete with the barge industry through their links to Pacific Northwest (PNW) ports. Potentially, a reduction or increase in rail rates to the PNW will result in a corresponding increase or decrease in rail grain shipments to the Pacific Northwest, therefore, reducing or increasing the amount of grain shipped by barge on the inland waterways. Railroads and trucks may also complement barge transportation since they are typically used to transport grain to the river. If the rate associated with complementary rail or truck grain carriage increases, it is likely that the quantity of grain shipped to the river will diminish. Accordingly, the demand for grain barge traffic would decrease or shift to the left. Conceptually, ocean carrier transportation rates may also influence grain barge demand on the upper Mississippi. A relatively high ocean freight rate linking lower Mississippi River ports to world importing regions may adversely affect grain barge demand on the upper Mississippi River, whereas comparatively low ship rates may increase grain barge demand.

Obviously, floods and droughts impact the navigability of the inland waterway. When a flood or drought occurs, barge demand may be weakened. Similarly, grain barge demand may be influenced by seasonal factors. During the grain harvest season, the demand for grain barge service may increase. In the winter, the upper Mississippi River is typically not navigable so grain barge demand will be nonexistent.

\section{VARIABLES AND DATA}

This section offers a brief discussion of selected variables used to measure grain barge demand on the upper Mississippi River. Data to estimate these relationships is monthly and extends from 1992 through 1999. Table 1 relates the definition of variables included in the study. The descriptive statistics for continuous variables are presented in Table 2.

Variables to estimate the upper Mississippi River's grain barge demand equations included the following: (1) quantity of grain shipped by barge per month and its lagged term (BQUM), (2) two lagged dependent variables $\left(\mathrm{BQUM}_{\mathrm{t}-1} \text { and BQUM } \mathrm{t}_{\mathrm{-12}}\right)^{1}$, (3) grain barge tariff rate (BRNI), (4) export grain demand at the lower Mississippi River ports (GEXPQ), (5) domestic grain demands (TCDOM), (6) regional grain supply (GSTOCKUM), (7) rates of competing and complementary transportation modes (OCEANS, RRMR, RRPNW), and (8) dummy variables (WINTER, FLOOD). BQUM represents the quantity of grain shipped per month from the upper Mississippi River to the lower Mississippi River port area. It is grain that originated on that segment of the Mississippi River extending from Minneapolis to Lock 24. These unpublished data were generated 
Table 1: Definition of Variables in Grain Barge Demand Equations for Upper Mississippi River

\begin{tabular}{|c|c|}
\hline Variables & Definitions \\
\hline $\mathrm{BQUM}_{i}$ & $\begin{array}{l}\text { Quantity of grain entering segment of upper Mississippi River that extends through Iowa } \\
\text { and Minnesota in month } i \text { (1,000 tons) }\end{array}$ \\
\hline $\mathrm{BRNI}_{i}$ & North Iowa grain barge rate in month $i$ (\$/ton) \\
\hline $\mathrm{GEXPQ}_{i}$ & Quantity of grain exported at Mississippi Gulf ports in month $i$ (1,000 ton) \\
\hline GSTOCKUM $_{i}$ & Quantity of grain stocks at Minnesota and Iowa in month $i(1,000 /$ tons $)$ \\
\hline $\mathrm{TCDOM}_{i}$ & Total domestic corn consumption in month $i$ ( 1,000 tons $)$ \\
\hline $\mathrm{RRPNW}_{i}$ & Rail rate for grain to Pacific Northwest ports in month $i(\$ /$ ton mile) \\
\hline OCEANS $_{i}$ & $\begin{array}{l}\text { Spread in ocean freight rates between Mississippi Gulf and Pacific Northwest to Japan in } \\
\text { month } i \text { (\$/ton) }\end{array}$ \\
\hline $\mathrm{RRMR}_{i}$ & $\begin{array}{l}\text { Rail rate for Minnesota originated grain shipped to upper Mississippi River elevators in } \\
\text { month } i \text { (\$/ton) }\end{array}$ \\
\hline WINTER & Dummy variable for winter quarter: December, January, February $=1$; others $=0$. \\
\hline FLOOD & Dummy variable for river closure caused by flood: flood $=1$; no flood $=0$. \\
\hline
\end{tabular}

Table 2: Statistical Summary of Variables Included in Grain Barge Demand Equations

\begin{tabular}{|c|c|c|c|c|c|}
\hline Variables & Unit & Mean & $\begin{array}{c}\text { Standard } \\
\text { Deviation }\end{array}$ & Minimum & Maximum \\
\hline BQUM & 1,000 tons & $1,738.65$ & $1,057.13$ & 1.85 & $3,504.92$ \\
\hline BRNI & $\$ /$ ton & 10.40 & 3.33 & 5.51 & 19.26 \\
\hline GEXPQ & 1,000 tons & $4,615.70$ & $1,158.33$ & $2,287.21$ & $7,310.14$ \\
\hline GSTOCKUM & 1,000 tons & $52,493.78$ & $23,202.22$ & $6,674.90$ & $10,3231.90$ \\
\hline TCDOM & 1,000 tons & $16,113.98$ & $4,089.74$ & $8,393.51$ & $24,702.31$ \\
\hline RRPNW & $\$ /$ ton mile & 0.014 & 0.001 & 0.011 & 0.018 \\
\hline OCEANS & $\$ / \mathrm{m}$. ton & 9.56 & 3.11 & 0.91 & 15.95 \\
\hline RRMR & $\$ /$ ton mile & 0.038 & 0.008 & 0.026 & 0.077 \\
\hline
\end{tabular}


by the Tennessee Valley Authority and provided by the Agricultural Marketing Service (AMS), U.S. Department of Agriculture (USDA). Corn and soybeans are the primary grains shipped by barge on the upper Mississippi River. Figure 2 shows monthly grain shipments on the upper Mississippi River over the study period: peak flows typically occur during the spring and fall seasons. The north Iowa grain barge rate (BRNI) was adopted as a proxy for barge rates linking the upper Mississippi River to lower Mississippi River ports. It is a spot grain barge rate collected by AMS, USDA by surveying barge industry personnel (USDA/AMS, 2003). The BRNI rate is unavailable in the winter because the river is closed to navigation. The upper Mississippi River grain barge rate has strong seasonality with the peak rate often occurring between September and November (Figure 3). The average north Iowa grain barge rate is $\$ 10.40$ per ton, and grain shipments on the upper Mississippi average 1.7 million tons per month (Table 2).

Grain exports at lower Mississippi River ports (GEXPQ), provided by AMS, USDA (USDA/AMS, 2003), served as a proxy for foreign grain demand. The average quantity of grain exported per month at lower Mississippi River ports is 4.6 million tons (Table 2). Corn is the primary grain produced in the Corn Belt and it is exported primarily to lower Mississippi River and Pacific Northwest ports.

\section{Figure 3: North Iowa Grain Barge Rate on the Upper Mississippi River, dollars/ton}

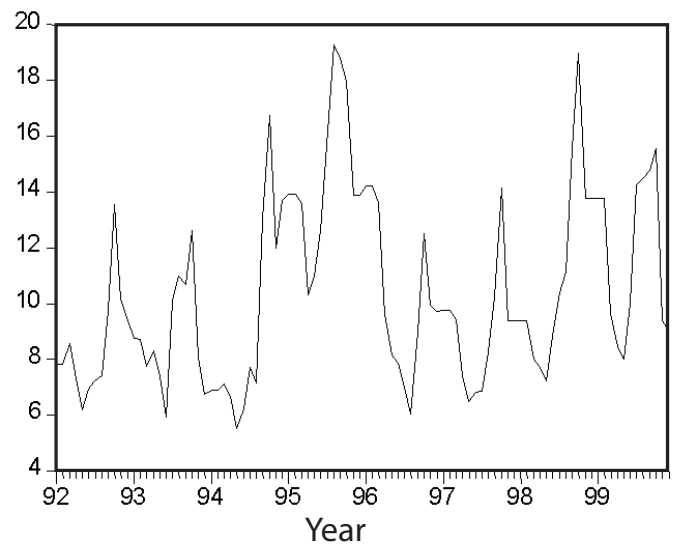

Grain stocks in Minnesota and Iowa (GSTOCKUM) represent regional grain supplies. These data were obtained from the
Economic Research Service, USDA (USDA/ ERS, 2003). Grain stocks are recorded quarterly, hence the need to interpolate the quarterly statistics for purposes of generating monthly values. The combined mean grain stock levels in Minnesota and Iowa were about 52.5 million tons per month (Table 2). Domestic demand for corn and soybeans was represented in the estimated grain barge equation by total domestic corn consumption (TCDOM). Domestic corn consumption (TCDOM) represents all corn consumed in the United States (USDA/ERS, 2003).

Transportation rates of complementary and competing transportation modes are also included in the grain barge demand equation. The spread or difference in the U.S. Gulfto-Japan and the PNW-to-Japan ocean grain freight rates (OCEANS) is included and is calculated by subtracting the PNW rate-to-Japan from the U.S. Gulf-to-Japan rate. In addition, railroad rates from Minnesota origins to upper Mississippi River elevators (RRMR) and from west Minnesota to the PNW (RRPNW) are included. Data on grain ship rates came from the AMS, USDA (USDA/AMS, 2003) while the unpublished annual Carload Waybill Sample ranging between 1992 and 2001, provided by the AMS, was the source of railroad rates. Rail service from Minnesota origins to the upper Mississippi River elevators is viewed as complementary to barge transportation (RRMR) while railroad rates from west Minnesota to the PNW (RRPNW) offer competition to grain barge demand. The railroad rates for grain shipments from Minnesota or Iowa to the Mississippi Gulf is not included here because more than $90 \%$ of the export-destined grain at the Mississippi Gulf is transported via the Mississippi River from the north central production region (USDA/AMS, 2003). This phenomenon is supported by the limited rail movements in the waybill data from the north central region to lower Mississippi River ports. Hence, it is likely that the influence of these rail rates on barge demand is modest.

The flood dummy variable (FLOOD) is included to capture the impact of floods on grain barge demand. In general, the entire river will not close if floods occur in a particular region; however, a regional flood may cause some locks to be inaccessible, which may 
divert the demand from barge to other modes. This dummy variable is generated from the Rock Island District's flood information, available at the Navigation Information Connection of the U.S. Army Corps of Engineer (U.S. Army Corps of Engineers, 2002a). A value of 1.0 is included for those months when floods are recorded, while a 0 represents remaining months.

\section{METHODOLOGY AND RESULTS}

To estimate the structural demand equation for grain barge transportation on the upper Mississippi River, both ordinary least squares (OLS) and two-stage least squares (2SLS) are employed. This is done because of the concern regarding the endogeneity of several explanatory variables such as barge rates (BRNI) and rates of other transportation modes (RRMR, RRPNW, OCEANS). Since equation (3) is a demand equation for barge transportation, theoretically, the quantity (BQUM) and the price (BRNI) for barge service is jointly determined. Therefore, a simultaneous bias may occur and the BRNI variable may be correlated with the residual, which makes the OLS estimates biased and inconsistent. Rates of other transportation modes (RRMR, RRPNW, and OCEANS) are considered as the potential endogenous variables because their transportation services may react to other's pricing strategies. Results are presented in two sections, OLS and 2SLS. A Hausman specification test (Hausman, 1978) was conducted to compare these two estimates and to examine the consistency of OLS estimates.

\section{OLS Estimates}

Several econometrics tests were conducted to examine the quality of the ordinary least square (OLS) results (Quantitative Micro Software, 1994). The residual tests, including correlograms of squared residuals, normality test, serial correlation Lagrange Multiplier (LM) test, autoregressive conditional heteroskedasticity (ARCH) LM test, and White's heteroskedasticity test were conducted for the grain barge demand models. The estimated grain barge demand equation generally performed well in the residual test. In addition, the Augmented Dickey-Fuller (ADF) test was applied to the residuals from the ADL equation. The null hypothesis of non-stationarity was rejected (ADF statistic of -3.872$)^{2}$, which indicates that the residuals generated from ADL estimation are a stationary series. However, stability tests consisting of the Chow breakpoint test and CUSUM of squares test indicate the estimated parameters are not stable across various time periods. The closing of the river during December, January, and February and the absence of rate and shipment data for these months complicate the estimation of the upper Mississippi River grain barge demand equations. This is the likely reason for the inferior results associated with the river grain barge demand equations.

Table 3 includes regression results of the grain barge demand equations for the upper Mississippi River. The estimated coefficient of each variable, except the dummy variables, is an elasticity. The elasticity measures the percent change in the dependent variable (quantity of grain transported by barge on the river) associated with a $1 \%$ change in a righthand side or explanatory variable. The expected negative relationship between barge rate (BRNI) and the quantity of grain moved by barge on the upper Mississippi River is observed in the estimated equation. The elasticity of the grain barge rate is -0.479 , indicating grain barge demand is inelastic with respect to grain barge rate. The t-statistic associated with the BRNI variable $(-1.621)$ indicates that barge rate is statistically significant at the $10 \%$ level. The quantity of grain exported at lower Mississippi River ports (GEXPQ) affects grain barge demand in a positive manner and is significant at the $1 \%$ level. The estimated elasticity of 1.197 implies that a $1 \%$ increase in the export grain demand will generate more than a $1 \%$ increase in grain barge demand. As expected, there is a positive relationship between grain stocks in Minnesota and Iowa (GSTOCKUM) and grain barge demand on the upper Mississippi River. The GSTOCKUM variable was not statistically significant. Total domestic corn consumption (TCDOM) representing domestic corn demand has a negative influence on grain barge demand and is not statistically significant.

The positive relationship between railroad rates from Minnesota to Pacific Northwest ports (RRPNW) and grain barge demand is as 
Table 3: Summary of OLS Grain Barge Demand Equations for Upper Mississippi River

\begin{tabular}{|c|c|c|}
\hline Variables $^{1,2}$ & Coefficient & t statistic \\
\hline $\mathrm{BQUM}_{t I}$ & 0.241 & $4.130^{* * *}$ \\
\hline $\mathrm{BQUM}_{t 12}$ & 0.287 & $2.611^{* *}$ \\
\hline $\mathrm{BRNI}_{t}$ & 0.479 & $1.621^{*}$ \\
\hline $\mathrm{GEXPQ}_{t}$ & 1.197 & $2.926^{* * *}$ \\
\hline GSTOCKUM $_{t}$ & 0.205 & 1.157 \\
\hline $\mathrm{TCDOM}_{t}$ & 0.498 & 1.533 \\
\hline $\mathrm{RRPNW}_{t}$ & 0.267 & 0.333 \\
\hline OCEANS $_{t}$ & 0.008 & 0.055 \\
\hline $\mathrm{RRMR}_{t}$ & 0.789 & $1.875^{*}$ \\
\hline WINTER & 2.112 & $6.259^{* * *}$ \\
\hline FLOOD & 0.666 & $2.140^{* *}$ \\
\hline CONSTANT & 3.935 & 0.676 \\
\hline Used Obs. (N) & 84 & \\
\hline Adj. $R^{\wedge} 2$ & 0.790 & \\
\hline
\end{tabular}

expected; it suggests that a higher railroad rate to the PNW will divert grain exports from the PNW to the upper Mississippi River barge fleet. However, the influence of RRPNW on grain barge demand is not statistically significant. An increase in the spread between the U.S. Gulf-toJapan and the Pacific Northwest-to-Japan ocean freight rates (OCEANS) will conceptually make grain exports from lower Mississippi River ports less competitive than exports from the PNW. Consequently, the demand for grain barge transportation on the upper Mississippi River would be reduced with a widening in the ship rate spread, hence a negative sign is expected and observed on the OCEANS variable. The lack of statistical significance suggests the influence of the ocean freight rate spread may be modest.
The RRMR variable has the expected negative sign and is significant at the $10 \%$ level. The estimated elasticity of the RRMR variable is -0.789 indicating that a $1 \%$ increase in RRMR will reduce the quantity of grain transported on the River by about $0.8 \%$.

The upper Mississippi River is not navigable in December, January, and February. Results confirm that grain barge demand dramatically declines in this period. The WINTER variable is highly significant ( $1 \%$ level) and with a negative sign. The flood variable (FLOOD), a dummy variable, is used to evaluate the impact of upper Mississippi River floods on grain barge demand. As expected, the FLOOD variable has a negative sign, and is significant at the $5 \%$ level. 


\section{SLS Estimates}

Since BRNI, RRMR, RRPNW and OCEANS are treated as endogenous, identification requires at least four instruments (Baltagi, 2002). The instruments must be exogenous variables that are uncorrelated with the residual term in the demand equation. The instrument variables selected for barge rate (BRNI) are a lagged term of barge rate and the number of barges available on the river each month. The lagged barge rate was selected as an instrument because it would not be affected by current barge demand. The selection of available barges on the river as an instrument variable was based on the assumption that this variable was linked to supply rather than the demand of the barge industry (Panel D, Figure 1). Therefore, these two instruments are viewed as exogenous and relevant to the BRNI variable. The number of available barges on the river was measured as the upbound empty barges passing through Lock 27 each month, which was generated from the Operation \& Maintenance of Navigation Installations (OMNI) reports (U.S. Army Corps of Engineers, 2003). For the rates of other transportation modes (RRPNW, RRMR, OCEANS), the lagged term of each variable, diesel price, and the wage index for transportation and warehouse industries are the selected instruments. Diesel price and wage index are shifters of the supply curve for transportation services, thus fitting the exogeneity and relevance condition necessary for instruments. Diesel price was available at the website of the U.S. Department of Energy (USDOE, 2003) while the wage index was collected through the Bureau of Labor Statistics at the U.S. Department of Labor (USDOL, 2003).

The 2SLS estimates of the grain barge demand equations are reported in Table 4 . The sign of each variable in the demand equation remained the same except the RRPNW variable. The barge rate (BRNI) elasticity increased to -0.578 but became insignificant. The elasticity of grain exports at lower Mississippi Gulf ports (GEXPQ) increased modestly from 1.197 to 1.248 , and remains significant at the $5 \%$ level. The elasticity associated with the regional grain stocks variable (GSTOCKUM) increased about $36 \%(0.205$ to 0.279$)$ but was non-significant as was the total domestic corn consumption (TCDOM). Interestingly, the rates for other transportation modes were not significant. Thus, grain exports, winter season and flood dummy variables are the only unlagged explanatory variables that significantly influenced barge demand.

The purpose of the Hausman specification test (Hausman, 1978) is to test the hypotheses of bias or inconsistency of an estimator. The null hypothesis of this test is $H_{0 ;} E(u / X)=0$ versus $H_{1}$; $E(u / X) \neq 0$, where the $u$ is the residual term and the $X$ represents the regressors. Two estimators are needed to conduct this test. In this study, the Hausman test is based on the difference between the OLS and 2SLS estimators. Failing to reject the null hypothesis implies that the OLS estimators are consistent. The Hausman test statistic for this model is 2.16 and is asymptotically distributed as $\chi_{12}^{2}$. This was found to be insignificant, which indicates that the 2SLS and OLS estimates are not significantly different given the choice of instruments and the model specification. Thus, the 2SLS method is not preferred over OLS.

Since the OLS estimates were found to be consistent (Hausman test), additional attention is focused on the grain barge demand price elasticity. The grain barge demand elasticities presented in Tables 3 and 4 are viewed as shortrun elasticities. Because the estimated demand equation is an autoregressive distributed lag model, we can examine how barge rate (BRNI) affects the demand for barge transportation in the long run following the procedure of Davidson and MacKinnon (1993). By using the estimated coefficients of the lagged terms of the dependent variable $\left(\mathrm{BQUM}_{\mathrm{t}-1}\right.$ and $\left.\mathrm{BQUM} \mathrm{t}_{\mathrm{t}-12}\right)$, long-run grain barge demand price elasticities were obtained for the upper Mississippi River. Short-run own-price elasticity was estimated to be -0.479 while the calculated long-run price elasticity was -1.015 [-0.479/(1-0.241-0.287)], implying that a $1 \%$ increase in the grain barge rate will reduce grain barge demand about $1 \%$ in the long run. 
Table 4: Summary of 2SLS Grain Barge Demand Equations for Upper Mississippi River

\begin{tabular}{|c|c|c|}
\hline Variables ${ }^{1,2}$ & Coefficient & $\mathrm{t}$ statistic \\
\hline $\mathrm{BQUM}_{t 1}$ & 0.255 & $4.147^{* * *}$ \\
\hline $\mathrm{BQUM}_{t 12}$ & 0.290 & $2.512^{* *}$ \\
\hline $\mathrm{BRNI}_{t}$ & 0.578 & 1.205 \\
\hline $\mathrm{GEXPQ}_{t}$ & 1.248 & $2.180^{* *}$ \\
\hline GSTOCKUM $_{t}$ & 0.279 & 1.301 \\
\hline $\mathrm{TCDOM}_{t}$ & 0.317 & 0.841 \\
\hline $\mathrm{RRPNW}_{t}$ & 0.853 & 0.424 \\
\hline OCEANS $_{t}$ & 0.170 & 0.771 \\
\hline $\mathrm{RRMR}_{t}$ & 0.316 & 0.317 \\
\hline WINTER & 2.078 & $5.625^{* * *}$ \\
\hline FLOOD & 0.724 & $2.137^{* *}$ \\
\hline CONSTANT & 10.377 & 0.762 \\
\hline Used Obs. (N) & 84 & \\
\hline $\operatorname{Adj} . R^{\wedge} 2$ & 0.778 & \\
\hline
\end{tabular}

\section{CONCLUSION}

The upper Mississippi River is a critical artery in the U.S. inland waterway system and of great importance to U.S. agriculture. Knowledge of grain barge demand on the River is important to the barge industry, grain producers and authorities that maintain and manage the lock system on the river. It is particularly critical today because of the controversies surrounding the expansion of the aged lock system on the river. Economic benefits from inland waterway transportation improvements should be based on demand schedules representing the willingness to pay for improved navigability of the waterway. The areas under the demand function measure the gross benefits from waterway improvement. The purpose of this study is to estimate grain barge demand for the upper Mississippi River and develop an improved understanding of forces impacting the demand.

Some notable findings are reported in this paper. Barge rates have a negative effect on grain barge demand or the quantity of grain transported by barge from upper Mississippi River origins to lower Mississippi River ports. A $1 \%$ increase in the grain barge rate will lower quantity transported by barge an estimated $0.5 \%$ in the short-run. For a long-run perspective, the own-price elasticity is elastic (-1.015) under the ceteris paribus assumption.

Foreign grain demand, as measured by quantities of grain exported at lower Mississippi River ports, has an important influence on grain barge demand. This is reasonable because grain barge demand is a derived demand that 
depends on excess demands associated with the international grain market. The export demand elasticity was found to be elastic (1.197) for the upper Mississippi River grain barge demand model. Increases in total domestic corn consumption is negatively related to quantities of grain transported by barge on the river. The elasticity associated with domestic grain demand is about -0.5 , but was not statistically significant.

Competing and complementary transportation modes may have an affect on upper Mississippi River grain barge demand; however, the results of this study are not statistically significant regarding most of these modes. For example, lower railroad rates linking Minnesota origins to Pacific Northwest ports was thought to be associated with reductions in grain transport on the upper Mississippi; however, the influence was not statistically significant. In contrast, the railroad rate linking Minnesota origins to upper Mississippi River elevators was found to be a statistically important explainer of upper Mississippi River grain barge demand, with increasing railroad rates associated with reduced grain barge movements on the upper Mississippi River. Ocean grain freight rates were not statistically important explainers of grain barge demand on the upper Mississippi. As expected, floods and the winter season have statistically important impacts on upper Mississippi River grain barge demand. Floods on the upper Mississippi reduce grain barge demand, as does the winter season when the river is closed to navigation.

In summary, grain barge demand on the upper Mississippi River is influenced by barge rates, foreign grain demands localized to lower Mississippi River ports, the rail rate for Minnesota-originated grain shipped to the Mississippi River, the winter season, and floods. In general, evaluated complementary and substitute transportation service did not yield statistically significant results.

\section{Endnotes}

1. The length of lag is determined by the Schwartz criterion (Schwartz, 1978). Based on the Schwartz test statistic, we select one- and twelve-lag of dependent variables in the model. Those two lagged dependent variables present some economic meanings within the context of barge transportation. The first lagged dependent variable, $\mathrm{BQUM}_{\mathrm{t}-1}$, is used to measure the influence of barge movement in previous month, while the second lagged dependent variable, $\mathrm{BQUM}_{\mathrm{t}-12}$, is included to evaluate the seasonality pattern that evolved every twelve month (Figure2).

2. The critical value at $5 \%$ significant level of the augmented Dickey-Fuller (ADF) test here is approximately -3.15 . The critical value of the ADF test associated with the generated regressors is lower compared to that on original (not generated) data (Granger and Newbold, 1986). Although the critical value in this case is lower than that for non-generated regressors, the ADF statistic of -3.872 indicates the residuals from the ADL models do not exhibit non-stationary behavior.

\section{References}

Babcock, M.W. and W. German. "Forecast of Water Carrier Demand to 1985." Proceedings of the Transportation Research Forum 24, (1983): 249-257.

Babcock, M.W. and X. Lu. "Forecasting Inland Waterway Grain Traffic.” Transportation Research Part E 38, (2002): 65-74.

Baltagi, Badi H. Econometrics. Third edition, Springer, Berlin, 2002.

Beuthe, M., B. Jourguin, J. Geerts, and C. Ha. "Freight Transportation Demand Elasticities: A Geographic Multimodal Transportation Network Analysis." Transportation Research Part E 37, (2001): 253-266. 
Boyer, K.D. Principles of Transportation Economics, Addison-Wesley, Massachusetts, 1997.

Davidson, R. and J.G. MacKinnon. Estimation and Inference in Econometrics. Oxford University Press, New York, 1993.

Fellin, L. and S. Fuller. "Effect of Proposed Waterway User Tax on U.S. Grain Flow Patterns and Producers." Journal of the Transportation Research Forum 36, (1997): 11-25.

Granger, C.W.J. and P. Newbold. Forecasting Economic Time Series. Second edition, Academic Press, Inc., Orlando, 1986.

Harnish, G. and J. Dunn. "A Short-Run Analysis of Grain Barge Rates on the Mississippi River System." Proceedings of the Transportation Research Forum 40, (1998): 557-572.

Hauser, R.J., J. Beaulier, and C.P. Baumel. "Impacts of Inland Waterway User Fees on Grain Transportation and Implied Barge Rate Elasticities.” The Logistics and Transportation Review 21, (1985): 37-47.

Hausman, J.A., “Specification Tests in Econometrics.” Econometrica 46, (1978): 1251-1272.

Miljkovic, D., G.K. Price, R.J. Hauser, and K.A. Algozin. "The Barge and Rail Freight Market for Export-Bound Grain Movement from Midwest to Mexican Gulf: An Econometric Analysis." Transportation Research Part E 36, (2000): 127-137.

Oum, T.H., "Derived Demand for Freight Transport and Inter-modal Competition in Canada." Journal of Transport Economics and Policy 13, (1979): 149-168.

Quantitative Micro Software. Eviews 3 Users Guide. 1994.

Schwartz, G. "Estimating the Dimension of A Model." Annals of Statistics 6, (1978):461-4.

Tang, X. "Time Series Forecasting of Quarterly Barge Grain Tonnage on the McClellan-Kerr Arkansas River Navigation System.” Journal of the Transportation Research Forum 40, (2001): 91-108.

U.S. Army Corps of Engineers, Navigation Information Connection (2003). http:// www.mvr.usace.army.mil/navdata/flood.htm.

U.S. Army Corps of Engineers, Operation \& Maintenance of Navigation Installations Reports (2002a) http://www.mvr.usace.army.mil/mvrimi/omni/webrpts/omni_gr/omni_criteria.asp?report_ name $=$ RPT01.

U.S. Army Corps of Engineers, Waterborne Commerce Statistics (2002b). http:// www.wrsc.usace.army.mil/ndc/wcsc.htm.

U.S. Department of Agriculture, Agricultural and Marketing Service, Grain Transportation Report (2003) http://www.ams.usda.gov/tmdtsb/grain/.

U.S. Department of Agriculture, Economic Research Service. Feed Grain Data Delivery System (2003). http://www.ers.usda.gov/db/feedgrains/. 
U.S. Department of Energy, Energy Information Administration. Monthly Energy Review: Energy Prices (2003). http://www.eia.doe.gov/emeu/mer/prices.html.

U.S. Department of Labor, Bureau of Labor Statistics. Consumer Price Index-Urban Wage Earners and Critical Workers: U.S. Transportation (2003). http://data.bls.gov/cgi-bin/ surveymost?cw.

Wilson, M.A., and P.E. Sandor. "Forecast of Canadian Grain Shipments Through the St. Lawrence Seaway 1985-2000." Proceedings of the Transportation Research Forum 23, (1982): 578-588.

\section{Acknowledgments}

The authors thank participants of a 2004 Transportation Research Forum meeting session, particularly Wei Fan, and an anonymous referee for helpful comments. We are also grateful to Oral Capps and David A. Bessler for advice. Finally, we thank Nick Marathon and Chris Dager for their data work.

Tun-Hsiang Yu is a Ph.D. candidate at the Department of Agricultural Economics, Texas A\&M University. He earned a B.A. in shipping transportation and management at the National Taiwan Ocean University, Taiwan, and an M.S. in economics at the Iowa State University. His research interests are in agricultural marketing, logistics and international trade.

Stephen Fuller is Regent Professor in the Department of Agricultural Economics at Texas A\&M University. He earned a B.S. and M.S. in agricultural economics and Ph.D. in economics all from Kansas State University. His research interests focus on agricultural transportation and marketing issues. 